\title{
Lapsus Medicus
}

\section{Lapsus Medicus: "Thyroid goiter"}

\author{
Alfredo Pinzón • Bogotá, D.C.
}

\section{¿BOCIO TIROIDEO?}

El uso de la expresión "bocio tiroideo" es incorrecto, ya que se trata de un pleonasmo que debe ser evitado.

El bocio (Del bajo latín boč̆a) se define como el crecimiento anormal de la glándula tiroides, y no ocurre en ningún otro órgano del cuerpo humano, por lo tanto es redundante aclarar su localización anatómica.

Lo adecuado es mencionar el tipo de esta afección, por ejemplo: bocio difuso, bocio nodular, bocio tóxico, etc.

Por lo anteriormente mencionado, la expresión correcta para esta patología es:

\section{BOCIO}

\section{Fuentes:}

- Real Academia Española de la Lengua, consultado en: www.rae.es

- Cárdenas de la Peña E. Terminología Médica. Tercera Edición. McGraw-Hill Interamericana. México D.F. 1996

\footnotetext{
* Envíe sus inquietudes, sugerencias o comentarios a: actmedco@etb.net.co - alfredo.pinzon@ hus.org.co

Dr. Alfredo Pinzón Junca: Especialista en Medicina Interna y Psicoanálisis. Hospital Universitario de La Samaritana y Hospital Simón Bolívar. Comité de Educación y Comunicaciones de la ACMI®. Bogotá D.C. E-mail: alfredo.pinzon@hus.org.co - alfpin@hotmail.com Recibido: 07/III/2011 - Aceptado: 07/III/2011
} 